\title{
Enjambment - Irony, Wit, Emotion. A Case Study Suggesting Wider Principles
}

\author{
Reuven Tsur, Chen Gafni*
}

\begin{abstract}
This study submits to empirical investigation an old idea of Tsur's regarding the effect of enjambment on the perceived subtleness of irony in a poetic passage. We submitted two versions of a Milton passage to over 50 participants with "background in literary studies", ranging from undergraduates to tenured professors, asking them to rate the perceived subtleness of irony and forthrightness of expression. We received four incompatible combinations of relative subtleness and forthrightness in the two passages. Two of the combinations were logically reasonable (though resulting from opposite performances), and two were internally inconsistent. An analysis of these results revealed two sources of this discrepancy: enjambments can be performed in three different ways, and participants respond not to abstract enjambments, but to performed enjambments; and they act upon partly overlapping definitions of irony. Assuming different performances of the enjambment, both logically acceptable response patterns support our hypothesis. Yet, a large part of the responses in this study were incoherent to some extent. This highlights the difficulty in collecting subjective interpretations of complex aesthetic events. We discuss this methodological issue at length.
\end{abstract}

Keywords: enjambment; performance; irony; wit; emotion; cognitive poetics

\section{Introduction}

This paper has been extracted from a wider work in progress on SoundEmotion Interaction in Poetry, in which we explore, among other things, what are the proper methods to investigate the perceived qualities of sound in poetry. One of our main arguments is that emotional and ironic qualities in poetry cannot be reduced to a semantic analysis; rather, they emerge from the interaction of sound structure (versification), syntactic structure and meaning. We demonstrate our claim by analysing the effect of lineation on the perceived qualities of text.

\footnotetext{
* Authors' addresses: Reuven Tsur, Tel Aviv University, Tel Aviv 69978, Israel. E-mail: tsurxx@tauex.tau.ac.il; Chen Gafni, Bar-Ilan University 901 Ramat-Gan 5290002, Israel. E-mail: chen.gafni@gmail.com.
} 


\section{Theoretical background}

The current study can be phrased in the terms of several theoretical frameworks. We use the term "qualities" in a gestaltist sense to refer to properties directly perceptible by the senses. Accordingly, emotional and ironic qualities are "regional qualities" of poetic passages, that is, qualities of the whole passage, but not of its parts (Beardsley, 1958: 83-88).

In Wayne Booth's (1961:3) terms, we are interested in emotion or irony by way of showing rather than mere telling: in literature, you cannot avoid telling, but in some instances, the text also displays the perceptual structure of an emotion or irony.

To bring this distinction out, music, which has no semantic component, does display emotional qualities; in Ronald Hepburn's (1968) terms, when we say "this music is sad", we report that we have detected a structural resemblance between the music and some emotion. Thus, for instance, in Paradise Lost divergent structures may confer an emotional quality upon Milton's concrete story-telling or his attempts to "justify the ways of God to men".

\section{The methodological approach}

In the present academic climate, the prevalent method to explore sound-emotion interaction in poetry is to have recourse to Stimulus-Response (S-R) questionnaires with great numbers of "subjects" and statistical analysis of their results, imported from the social sciences. The ultimate goal of this approach is to make general claims at the population level, ignoring occasional, idiosyncratic responses. By contrast, we claim that, in the humanities and arts, such methodology is not always appropriate; by focusing on the population level and relying exclusively on quantitative measures, one may overlook more fine-grained patterns, which may be important and interesting on their own. In addition, analysing open-ended responses to complex aesthetic events can shed light on the cognitive processes within the individual, while examining quantitative measures can only tell us something about the result of these processes.

In the present discussion, we start out with a theoretical description of the texts and, based on introspection supported by gestalt theory, we made predictions as to the perceived quality of the passage. After running it in a seminar situation, we submitted the texts to "empirical" S-R test with a battery of over fifty participants. Unexpectedly, we obtained a welter of incompatible answers, from which we attempt here to reconstruct the process by which those answers had been reached. 


\section{Three Ways to Perform Enjambment}

Many scholars and critics take enjambment as a given of the text, irrespective of how you perform it. They frequently ignore that participants respond to a performed enjambment, and that participants who perform the enjambment differently respond to different aesthetic objects.

There is also some uncertainty about how enjambments can be performed. The received view (formulated by Seymour Chatman 1965) is that, having only one voice, a performer cannot convey two intonation contours at the same time; in case of conflicting intonation contours the vocal performer must choose one contour with its related meanings - of the sentence or the verse line - and suppress the other.

In his writings, Tsur proposes a third option: to see whether one can imagine or secure a performance that would simultaneously preserve in perception both the versification and the syntactic units. We argue that this may be achieved by having recourse to conflicting acoustic cues for continuation and discontinuation. In ordinary speech, we usually cue sentence ending by redundant acoustic cues: pause, falling intonation contour and slowing down the last word or speech sounds; when syntactic and versification units conflict, we use the same cues in opposition to one another. ${ }^{1}$ Consider three recorded performances of the lines

$1 . \quad$ Who best

Bear his mild yoke, they serve him best. His state

Is kingly: thousands at his bidding speed,

from Milton's "On His Blindness" sonnet. The sentence "His state/ is kingly" is run on from one line to the next one. In harmony with Chatman, one performer (Barrett) preserves syntactic continuity and suppresses the line ending (listen 2 ). Two other performers, on the contrary, indicate discontinuity at the

1 Tsur (1977: 134 and passim) put forward this conception speculatively. All the experts in instrumental phonetics said at the time that it could not be tested instrumentally. But Tom Barney (1990), without having heard of Tsur's work, found a workaround, proving its feasibility. Tsur $(1998 ; 2012)$ applied Barney's method to his comprehensive theory of poetic rhythm; later he published his first instrumental manipulation of performed enjambment according to these principles (Tsur 2000). A conception of "non-disambiguating intonation contours" had been proposed by Katherine Loesch (1965), attacked by Chatman (1966), with a rejoinder by Loesch (1966). The fourth edition of The Princeton Encyclopedia of Poetry and Poetics (Greene 2012) still puts forward Chatman's view of enjambment as the view, though it mentions Loesch (but not Tsur or Barney) in the references of the entry.

2 Sound files are available online at https://doi.org/10.12697/smp.2018.5.2.01. 
line ending by a pause and low intonation, suppressing syntactic continuity (Listen to Anonymous' and Leon Mire's readings of this sentence). ${ }^{3}$ Tsur (2012: 397-398) electronically manipulates the first performance, the one displaying syntactic continuity, so as to indicate, at the same time, discontinuity without a pause, by prolonging "state" and manipulating its intonation; he submitted "thousand" to the same manipulations, to indicate caesura (Listen to the manipulated version). The result indicates that at least one performance may be secured in which continuity and discontinuity can be perceived at the same time. Tsur calls such a performance a "rhythmical performance".

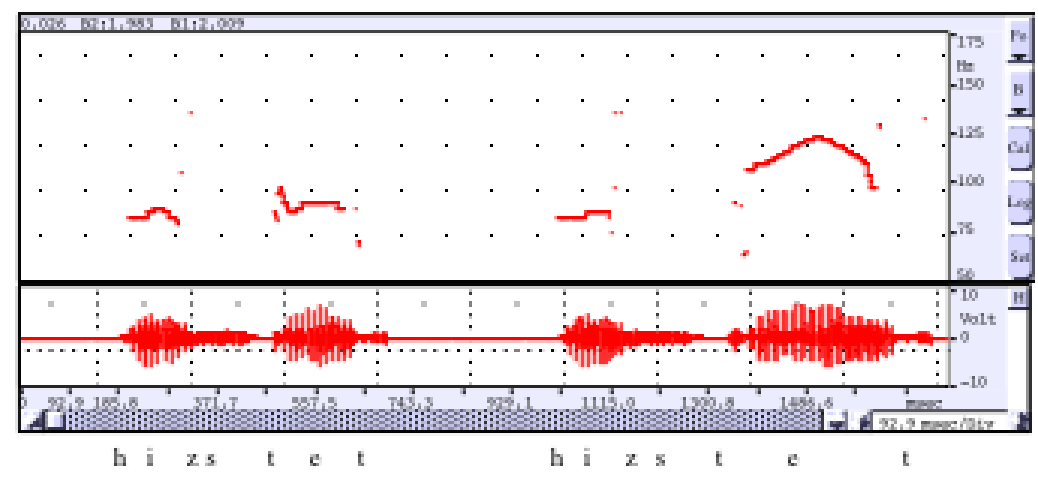

Figure 1. Wave plot and F0 plot of "His state" excised from the genuine and the doctored versions of "His state is kingly"

Listen to the readings reflected in Figure 1. The first (genuine) token of "state" is relatively short and bears a low, near-horizontal intonation contour. The second (doctored) token of "state" is longer, and bears a rising-falling intonation contour (Tsur 2012: 397-400).

\section{Enjambment and Shift of Meaning}

Scholars and critics are mostly interested in instances of enjambment where it effects shift of meaning in one way or other. Our view is that enjambment affects, first and foremost, the gestalt quality of the passage and only in the

3 Recorded readings of "On His Blindness":

(1) Sean Barrett: http://www.youtube.com/watch?v=q0RrfIEmYj0.

(2) Anonymous: http://classicpoetryaloud.podomatic.com/entry/2007-11-20T03_34_02-08_00.

(3) Leon Mire: http://ecaudio.umwblogs.org/milton-on-his-blindness-read-by-leon-mire/. 
minority of cases it affects meaning. Here we explore an instance where enjambment is supposed to affect not the ostensible meaning, but the perceived quality of irony.

In the foregoing example ("His state / Is kingly"), enjambment does not bring about a shift of meaning, only weakens the gestalt of the utterance, enhancing its emotional quality. In the ensuing example, we shall consider how enjambment may produce a shift of meaning and how performance may affect the perceived quality of that shift of meaning. We shall do this through an exchange between Natalie Gerber and Reuven Tsur regarding three lines in James Wright's poem "A Blessing". In her paper "Intonation and the Conventions of Free Verse", Natalie Gerber (2015) comments on Wright's final three lines:

'Suddenly I realize / That if I stepped out of my body I would break / Into blossom' (22-24). [...] [B]y placing the line ending between 'I would break' and 'Into blossom,' Wright interrupts our expectation that we read 'break into' as a phrasal verb, with a conventional meaning. Instead we are invited to hear a pause, reading 'I would break' and 'into blossom' as two intonational phrases and thus entertaining two semantic possibilities at once: that the speaker shatters, a meaning that goes with his stepping out of his body, and that he unexpectedly blossoms.

With reference to this ambiguity Tsur (Gerber, Smith 2015: 209) observes that his interest lies in the question how such an enjambment should be performed. Suppose we "hear a pause, reading 'I would break' and 'into blossom' as two intonational phrases and thus entertaining two semantic possibilities at once". Wit is the phenomenological quality of the sudden shift of mental set. Thus, in such a performance the sudden switch of meanings might have witty overtones. This would be, perhaps, in congruence with some interpretations of the poem. Tsur asks, however, whether one can imagine or secure a performance in which the two meanings blend more smoothly, that would suggest some more earnest attitude, in case someone endorses a different interpretation. The cosy atmosphere of the poem may indeed support such an interpretation. According to the present conception, one could pronounce the enjambment by having recourse to one intonational phrase, with no measurable pause between the two verse lines, suggesting at the same time discontinuity by lengthening the word 'break' and over-articulating the stop release of [k]. Thus, performing the two phrases of the enjambment as two intonational phrases with a pause between them is incompatible with the cosy atmosphere of the poem; it requires what we called a "rhythmical performance". 


\section{Milton vs. Milton - "Other Things Being Equal"}

In the ensuing discussion, we are considering two texts in which all "other things are equal"; in fact, identical: a passage by Milton and its version with rearranged lineation. We focus two of our principles on these two passages.

First, the performance of poetry is a problem-solving activity; participants may perform the same excerpt in different ways, thus providing different solutions to the same problems arising in a poem. But by that, they, in fact, respond, to different aesthetic objects, with different perceptual qualities. For instance, pausing at the line ending in an enjambment may suggest some assertive attitude as wit. By contrast, cuing discontinuity by more evasive vocal devices may suggest some more fine-textured attitude, as irony or emotions. In Milton's Paradise Lost, for instance, it usually lends some emotional force to "the great argument", but sometimes subtleness to its irony.

Secondly, to use Wayne Booth's distinction, emotions and attitudes can be conveyed by way of telling, namely by the meaning of words, or by way of showing, namely using poetic structures to generate some psychological atmosphere (that may, in turn, be individuated by the meaning of words, as specific emotions or attitudes as perceived qualities). The ultimate evidence for the impact of poetic structure on psychological atmospheres would be a comparison between the following two excerpts. They are literally identical and differ only in their poetic structure: in one, syntactic units run over line boundaries, in the other they end at line boundaries.

2. But wherefore thou alone? Wherefore with thee

Came not all Hell broke loose? Is pain to them

Less pain, less to be fled, or thou than they

Less hardy to endure? Courageous Chief,

The first in flight from pain, had'st thou alleg'd

To thy deserted host this cause of flight,

Thou surely had'st not come sole fugitive.

(Paradise Lost IV. 917-923)

3. But wherefore thou alone?

Wherefore with thee came not all Hell broke loose?

Is pain to them less pain, less to be fled,

Or thou than they less hardy to endure?

Courageous Chief, the first in flight from pain,

Had'st thou alleg'd to thy deserted host

This cause of flight, thou surely had'st not come

Sole fugitive. 
Excerpt 2 consists of a series of "straddled lines". These are sentences run-on from one line to another which themselves, when isolated, form an iambic pentameter line. The initial run-on lines of Excerpt 2 are rearranged (by James Whaler (1956: 20-21)) into end-stopped lines in Excerpt 3. This rearrangement affects the perceived quality of the passage. Excerpt 2 is perceived as fluid, whereas Excerpt 3 as more stable.

When the syntactic unit and the verse line coincide, they reinforce each other's shape, yielding "strong gestalts". When the syntactic unit is run on from one line to another, they blur each other, yielding "weak gestalts". Gestalt psychologists have produced empirical evidence that strong gestalts are typically perceived as rational, non-emotional, whereas weak gestalts typically display an emotional quality.

Leonard B. Meyer, who applies gestalt theory to music, that is, sequences of sounds without a semantic component, accounts for the association of weak and strong gestalts with emotional and intellectual qualities as follows. "Because good shape is intelligible in this sense, it creates a psychological atmosphere of certainty, security, and patent purpose, in which the listener feels a sense of control and power as well as a sense of specific tendency and definite direction" (Meyer 1956: 160).

The opposite applies to weak shapes and emotional qualities. We shall have to explain how such psychological atmospheres interact with meanings in poetry. We have noted, for instance, that the divergent structure in Excerpt 2 seems to affect not only emotional qualities, but irony too, rendering it subtler. Meyer's formulation may account for this effect too, precisely because it refers to a general psychological atmosphere individuated here as irony by the meaning of words, rather than directly to a specific attitude. The ironic attitude typically involves some kind of pretended ignorance, pretending to have no specific intentions. The "psychological atmosphere of patent purpose" inspired by the stronger gestalts in Excerpt 3 subverts, therefore, the tone of elusive ignorance in irony. Weak gestalts, divergent structures, may enhance, then, quite diverse attitudes. Rather than indicating an iconic relationship between sound and meaning, divergent structures generate "a psychological atmosphere of uncertainty, lack of patent purpose and definite direction", concreted by various kinds of contents in a variety of more specific emotions and attitudes. This conspicuously applies to irony as well.

The vast majority of our respondents agreed that the different lineation does affect the passages' perceived qualities. However, there was less consensus regarding the nature of the qualities.

Milton explicitly suggests that the passage is ironical or even sarcastic. The archangel Gabriel meets Satan on his way to the Garden of Eden, to whom 
he speaks "Disdainfully half smiling". Tsur asked students in a seminar situation at the University of Sussex, back in 1971: "Is irony equally subtle in the two passages?" Some students could discern no significant difference. But the rest were in agreement that irony seems to be 'somehow subtler' in Excerpt 2.

How can we explain this? Semantically and syntactically, the two passages are identical. Here we have tried to replicate these results in a more formal way, by asking participants to fill a questionnaire. As will be seen, the results were far from unanimous. We shall have to account for the different kinds of answers with one theoretical battery; and we shall also have to account, with the same theoretical battery, for the fairly unanimous results in the seminar situation, on the one hand, and the four radically different kinds of answers in the written questionnaire, on the other hand.

\section{The Empirical Study}

In our empirical study, we presented Excerpts 2 and 3 to our respondents with the following instructions:

The following two excerpts are versions of Paradise Lost IV. 917-923 and are literally identical; they differ in the correspondence of the syntactic units with the versification units. The archangel Gabriel meets Satan on his way to the Garden of Eden, to whom he says "Disdainfully half smiling": [EXCERPTs 2-3].

Read aloud the two passages, then consider the following claims and rate how much you agree with each of them $(1$ star $=\mathrm{I}$ completely disagree, 5 stars $=$ I completely agree):

1. In Excerpt 2 irony is subtler than in Excerpt 3.

2. In Excerpt 3 irony is subtler than in Excerpt 2.

3. Excerpt 2 is more forthright than Excerpt 3.

4. Excerpt 3 is more forthright than Excerpt 2.

5. Lineation does not affect the ironic quality of the passages.

6. Lineation does not affect the forthright quality of the passages.

In addition to evaluating the above claims, participants were also given the opportunity to leave comments on the exercise. We hoped that such comments would provide more detailed information about the participants' thought processes. 


\section{Procedure}

The task was a part of a larger online study on the perceived qualities of sound patterns in poetry. The experiment was run on the Qualtrics platform (https:// www.qualtrics.com).

\section{Participants}

Fifty-three participants completed the survey (age: mean: 40, range: 19-78; 32 women). All but two were native speakers of English and were residents of several countries, mainly the United States, Canada, and Israel. They had variable background in English poetry, from novice (high school or introductory university level) to expert (professors of literature specializing in English poetry). The distribution of literary experience of the participants is shown in Table 1.

Table 1. Level of literary training

\begin{tabular}{|l|l|}
\hline Level of literary training & Participants \\
\hline No formal training at university level & 1 \\
\hline $\begin{array}{l}\text { Basic university training (BA students majoring in English } \\
\text { literature, English teachers with no degree in literature) }\end{array}$ & 9 \\
\hline BA level \& MA students & 18 \\
\hline MA level \& PhD students & 11 \\
\hline PhD & 14 \\
\hline
\end{tabular}

Participants were recruited via university mailing lists and the PSYART forum. They were awarded an electronic gift card on the amount of 20GB for Amazon.

\section{Results}

We begin by analysing the claims concerning the effect of lineation on the quality of the excerpts. Figure 2 shows the distribution of responses to claim 5 ("Lineation does not affect the ironic quality of the passages") and Figure 3 shows the distribution of responses to claim 6 ("Lineation does not affect the forthright quality of the passages"). As can be seen, the overwhelming majority 
of participants rated claims 5-6 as 1 or 2 (median: 1 ), that is, they tend to agree that lineation does affect the ironic or forthright quality of the passage, in line with our hypothesis.

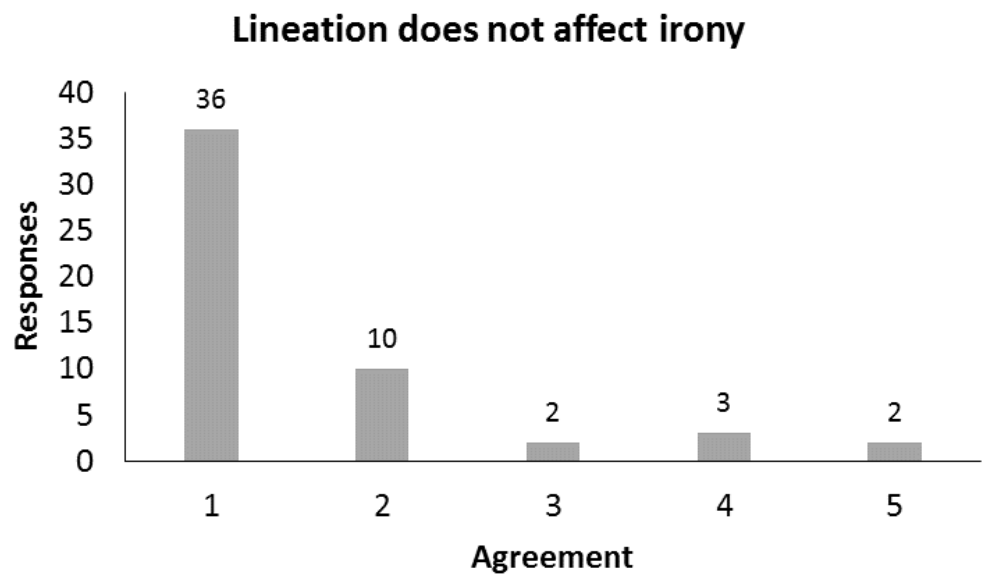

Figure 2. The effect of lineation on the ironic quality of the passage

\section{Lineation does not affect forthrightness}

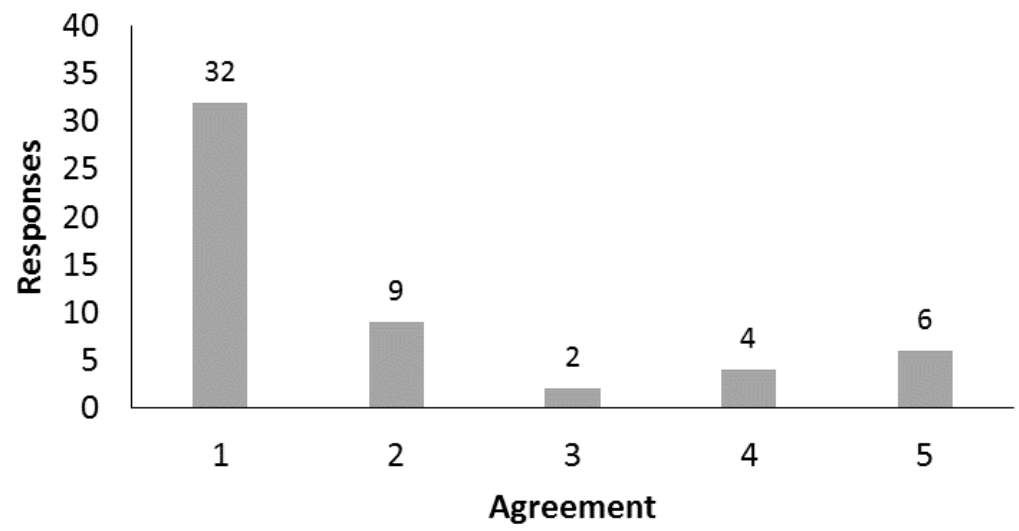

Figure 3. The effect of lineation on the forthright quality of the passage

Next, we analyse the judgements on the relative qualities of excerpts 2 and 3. Table 2 summarises the median ratings for each of the four claims. The median ratings are compared to the expected ratings according to our hypothesis. 
Table 2. Relative qualities of excerpts 2 and 3

\begin{tabular}{|l|r|r|}
\hline Claim & Median & Expected \\
\hline 1 ("In Excerpt 2 irony is subtler than in Excerpt 3") & 3 & 5 \\
\hline 2 (“In Excerpt 3 irony is subtler than in Excerpt 2") & 2 & 1 \\
\hline 3 ("Excerpt 2 is more forthright than Excerpt 3") & 2 & 1 \\
\hline 4 ("Excerpt 3 is more forthright than Excerpt 2") & 4 & 5 \\
\hline
\end{tabular}

In general, the median ratings were in the expected direction (i. e. towards the low or high end of the scale) but not as absolute. In what follows, we will account for this pattern of results. Table 3 summarises the results of pairwise Spearman correlations among claims 1-4. The table specifies the correlation coefficient (Spearman's $\rho$ ), its $p$-value, and the expected coefficient $(+1$ for synonymous claims, -1 for opposing claims).

Table 3. Pairwise Spearman correlations among claims 1-4. $P$-values indicate the probability of obtaining the correlation by chance. ${ }^{*}=$ the correlation is significantly different from zero

\begin{tabular}{|l|l|r|r|r|}
\hline Claim A & Claim B & Spearman's $\rho$ & Expected & $\mathbf{p}$ \\
\hline 1 & 2 & -0.61 & -1 & $9.8 \cdot 10^{-7}$ * \\
\hline 1 & 3 & -0.08 & -1 & 0.56 \\
\hline 1 & 4 & 0.30 & 1 & $0.03 *$ \\
\hline 2 & 3 & 0.12 & 1 & 0.40 \\
\hline 2 & 4 & -0.12 & -1 & 0.40 \\
\hline 3 & 4 & -0.69 & -1 & $1.0 \cdot 10^{-8}$ \\
\hline
\end{tabular}

As expected, claims 1 and 2 were significantly (negatively) correlated, and so were claims 3 and 4, since the claims in both pairs were contradictory (though the correlations were not perfect). Also, claims 1 and 4 were significantly (positively) correlated, but the correlation was much weaker. This result was expected too, since in our conception, irony and forthrightness are antonyms. The rest of the combinations were not significant $(1+3,2+3,2$ +4 ), as if "subtle" and "forthright" were unrelated in meaning (if they were regarded as synonyms, we would expect to find significant correlations in the opposite directions). These results were rather surprising and we will attempt to account for them by examining the coherence of the responses of individual participants. 
Given that claims 1 and 2 are contradictory and claims 3 and 4 are contradictory, we do not expect participants to assign similar ratings to claims in each pair. We can suspect that participants who did make such fallacies either did not understand the claims, were unable to evaluate their truthfulness, or chose a wrong value by mistake. One participant (a tenured professor of literature) commented on this task "I don't know what 'forthright' means in the last exercise". Accordingly, she assigned a rating of "1" to both claims 3 and 4, confirming that incoherent judgments in this task may result from misunderstanding. Such judgments should probably be excluded from the analysis since they do not represent a true evaluation of the claims, as defined in the task.

Note that since the claims in each pair $(1+2,3+4)$ are contradictory, we would expect, theoretically, that their ratings would be at the extreme opposites of the scale $(1 v s .5)$. However, we also accept judgments that show a weaker contrast (e. g., 2 vs. 4), which might suggest lack of certainty, or a general tendency to avoid the extreme points of the scale (Bishop, Herron 2015). These possible factors can also account for the mild median ratings of the claims observed in Table 2. In total, 8 participants gave a high rating or a low rating to both claim 1 and claim 2 or both claim 3 and claim 4 (one participant was incoherent in both pairs).

Interpreting responses at the mid-point of the scale (" 3 ") is more difficult. Recall that the rating scale in the experiment was defined as " 1 star = I completely disagree, 5 stars = I completely agree", while the mid-point was not labelled (though it probably should have been; see Nadler, Weston, Voyles 2015). " 3 " ratings can probably be understood as representing a lack of opinion, or lack of ability to evaluate the claim. In total, six participants gave a " 3 " rating to one claim and an extreme rating to its antonym (four participants did that in both pairs of opposing claims). We also consider such responses incoherent since they suggest that a participant was certain about the truthfulness of a claim but was uncertain about the truthfulness of its antonym.

In addition, some participants gave a " 3 " to rating to a pair of contradictory claims. We interpret such responses as an indication that the participant was unable to decide which claim was the correct one. Two participants demonstrated this pattern with respect to claims 1 and 2, and another two participants did the same with claims 3 and 4 . Note that each of these participants provided decisive responses for the claims in the other pair. This suggests that, for them, the subtlety of irony and the forthrightness of the text were unrelated in meaning.

After excluding the "incoherent" and uncertain responses, we were left with responses of 35 participants. Of them, 17 participants consistently claimed that irony in excerpt 2 was subtler than in excerpt 3 and that excerpt 3 was 
more forthright than excerpt 2 (we call this pattern of responses "Combination 1 "). Five participants were consistent in the opposite direction (hereinafter, "Combination 2"). The remaining 13 participants provided seemingly inconsistent judgments. Four of them judged irony to be subtler in excerpt 2 and at the same time that excerpt 2 was more forthright. The remaining nine participants judged excerpt 3 as containing subtler irony and being more forthright at the same time.

To summarize, 22 participants provided consistent responses. 17 of them followed "Combination 1", which is in accordance with our initial intuition. But, as will be seen, assuming different performances, the opposite responses pattern ("Combination 2") also support our hypothesis.

Nevertheless, the responses given by the majority of the participants in the study (31) suggest that they either (a) did not understand the statements they were asked to evaluate; or, (b) were unable to evaluate their truthfulness (e. g., did not detect a difference in the subtlety of the irony in the two excerpts); or, (c) had different conceptions of "irony" and "forthrightness" than the ones we relied on.

\section{Discussion}

Nearly a third ${ }^{4}$ of the participants in the study judged that "In Excerpt 2 irony is subtler than in Excerpt 3 and Excerpt 3 is more forthright than Excerpt 2". This is consistent with our initial hypothesis. On the other hand, five participants had the opposite interpretation. Both participant groups included individuals with extensive background in English literature, so it would be difficult to dismiss the responses by the smaller group as reflecting incompetence or misunderstanding of the task.

We would like to suggest that these seemingly inconsistent results foreground an interesting fact: that Milton's genuine passage is heavily enjambed, and that the performance of enjambments is not at all self-evident. Our exercise with Excerpt 1 may help to account for the applicability of both Combinations $\mathbf{1}$ and $\mathbf{2}$ as adequate answers in our experiment. In suggesting that irony is more elusive in Excerpt 2 than in 3, we assumed a "rhythmical performance", in which continuity and discontinuity may simultaneously be perceived.

What does such a performance sound like in Excerpt 2, as opposed to Excerpt 3? This comparison has been discussed in greater detail, with recorded

4 Or, $49 \%$ after excluding the contradictory and indecisive responses. 
performances, by Tsur (2012: 239-252). Excerpts 4 and $\underline{5}$ have been extracted from excerpts 2 and 3, respectively. Listen to these excerpts read by $\mathrm{JH}$, a graduate student of Linguistics and Modern English Literature at Lancaster University, who proved to be a masterful performer of rhythmic complexities in poetry.

4. But wherefore thou alone? Wherefore with thee

Came not all Hell broke loose?

$5 . \quad$ But wherefore thou alone?

Wherefore with thee came not all Hell broke loose?

Note the word "thee" in the two readings. In the reading of Excerpt 4, the listening ear discerns continuity and discontinuity at its boundary at the same time, just as demanded by the syntax and lineation. In the reading of Excerpt $\underline{5}$, the listening ear discerns continuity without discontinuity, as fit to its place in mid-line and mid-phrase. There is no measurable pause between "thee" and "came" in either reading. One may easily discern the means by which this difference is generated. The duration of "thee" is much longer in the reading of Excerpt 4 than of 5; and one hears a conspicuous rising-falling intonation contour on "thee" in the former, as opposed to an almost flat intonation curve in the latter.

A look at the graphs supports this impression. Note that the duration of "thee" is almost twice as long in Figure 4 as in Figure 5; the duration of /ð/ over three times as long (prolongation in this case indicates lack of progression). Note also that the pitch contour of the vowel of "thee" in Excerpt 5 is less obtruding (peak: $143 \mathrm{~Hz}$, minimum: $115 \mathrm{~Hz}$ ). In Except 4 the maximum pitch is about the same ( $147 \mathrm{~Hz}$ ) but the minimum is $67 \mathrm{~Hz}$ (that is, almost three times greater interval). Note, again, that in this case, enjambment does not necessarily contribute an additional meaning (as it does in Wright's poem, above); it merely weakens the gestalt of the utterance, generating a psychological atmosphere of uncertainty, lack of definite directions and patent purpose. 


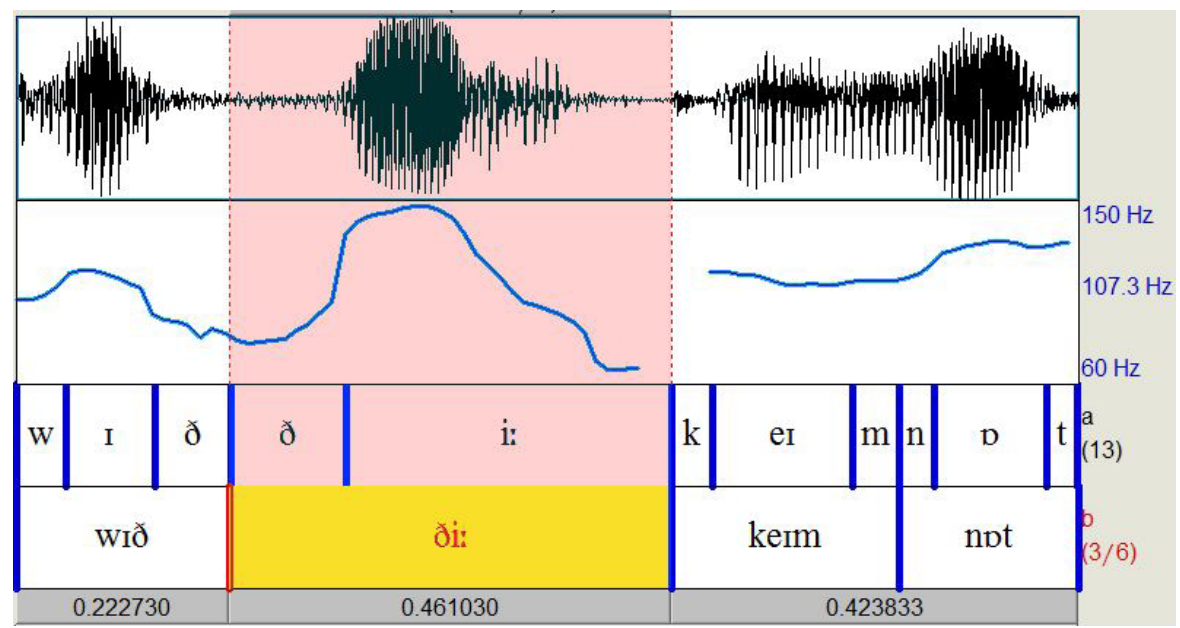

Figure 4. Waveform and intonation contour of "with thee came not" excised from a reading of Excerpt 4 by $\mathrm{JH}$

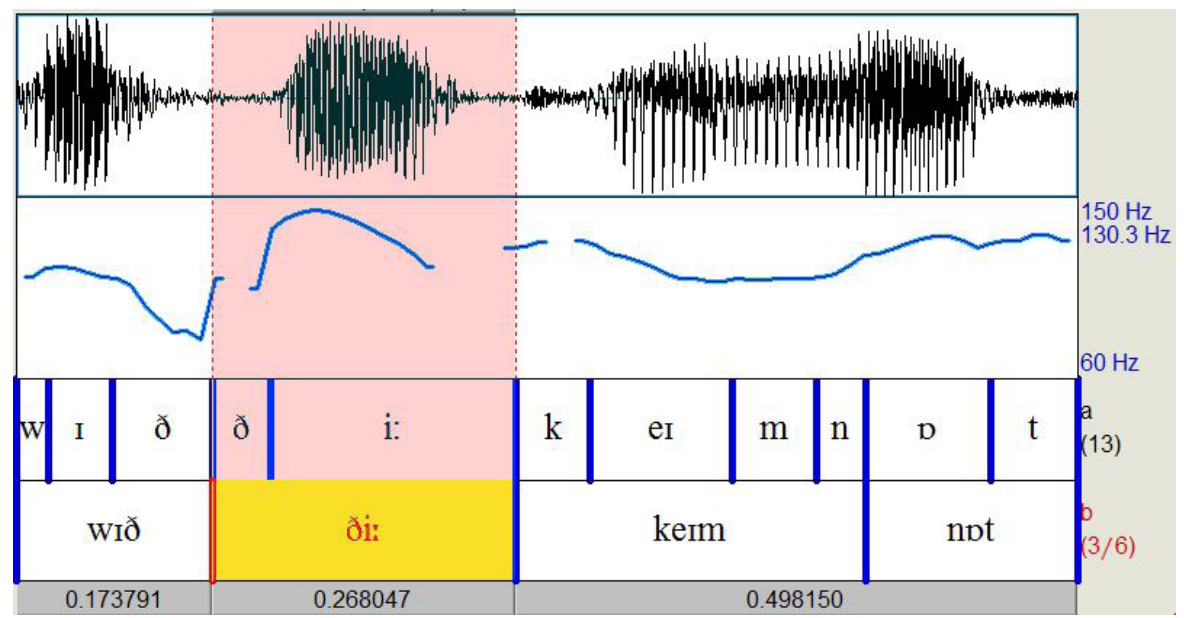

Figure 5. Waveform and intonation contour of "with thee came not" excised from a reading of Excerpt 5 by $\mathrm{JH}$

But, it would appear that in Excerpt 2 a considerable number of performers would follow Chatman, indicating discontinuity at the line ending and, by the same token, suppressing syntactic continuity. In this case, the sequel - if contradictory - may appear as a surprise, generating forthright wit. 
The discussion of the enjambment in Wright's poem, "That if I stepped out of my body I would break / Into blossom" may highlight the effects reported in Combinations 1 and 2. In addressing Satan as "Courageous Chief, / The first in flight from pain", the two phrases can be cued by separate intonation contours with a pause between them, in a way that presents the second, contradictory phrase as a surprise, generating forthright wit; in view of this, Excerpt 3 would appear less forthright, expressing subtler irony. Alternatively, in Excerpt 2 the two phrases can be performed as one intonational phrase, indicating discontinuity by less obtrusive means, so as to render the contradiction elusive irony.

What wit and irony have in common is contradictory implications; they differ in their degree of conspicuity. The aforementioned performances sharpen or tone down, respectively, the conspicuity of the contradiction. Briefly, respondents who offered Combination 2 may have performed the two phrases in Excerpt 2 with emphatically separate intonation contours. The different answers based on Combinations 1 and $\mathbf{2}$ became possible owing to two uncertainties involved. According to the foregoing analysis, there are three different ways to perform an enjambment, with different perceived qualities; and the border line between "wit" and "irony" is rather fuzzy (at any rate, many literary scholars use the two terms interchangeably).

The goal of the foregoing discussion was to account for the consistently opposite response patterns (i. e. Combinations 1 and 2). Yet, thirteen of the participants $(37 \%)^{5}$ provided a third response pattern (hereinafter, Combinations 3 \& 4), suggesting that, for them, "subtle" and "forthright" were synonymous in this context. Participants in both groups seemed to have relied on the dictionary meaning of "irony", but failed to distinguish "irony" from "wit". The hypothesized difference between the groups is in the way they performed the enjambment. Participants who judged excerpt 3 to be both more forthright and subtler seem to have paused at the line endings in Excerpt 2. On the other hand, participants who judged excerpt 2 to be both more forthright and subtler seem to have performed Excerpt 2 with mitigated cues for discontinuity. Some people seem to believe that irony at its best is blatant; we had a different conception in mind when putting the question.

To sum up. Theoretically, we found four possible combinations of "subtleness" statements and "forthrightness" statements. Assuming different performances, both combination 1 and its straightforward reverse (combination 2) support our research hypothesis. Excluding responses that are downright contradictory (18), these two options together represent $63 \%$ of the

5 After excluding the 18 contradictory and indecisive responses. 
"votes", with judgments based on Combination 1, presupposing a "rhythmical performance", forming the majority (49\%). Yet, a good deal of $37 \%$ of the judgments contradict our research hypothesis. We found good reasons to suppose that this was due to a different understanding of "irony" or "forthright".

Finally, why did we receive fairly unanimous responses in the seminar situation and systematically different responses in the questionnaire task in response to the same texts? There are many significant differences between the two conditions, but the most significant one is this. In the seminar situation, the tutor reads out the two texts before collecting impressions from students, whereas in filling out the questionnaire, each participant must produce his or her performance, having a choice between three possible kinds of solution. Consequently, all participants in the seminar situation responded to one defined, contrasted pair of performances. On the other hand, in the questionnaire situation, each participant responded to a potentially different contrasted pair of performances.

In addition to shedding light on the perceived effect of lineation, the present article also makes a methodological contribution. One of the gravest problems in an empirical study of the present kind is the problem of communication between experimenter and participants. To ensure clear, unambiguous communication, many empirical studies in the aesthetic domain confine themselves to rather simple, trivial issues. With increasing complexity of the questions involved, the difficulty of unambiguous communication increases as well. If the experimenter explains very clearly his question, he may suggest the expected answer too. If he tries to refrain from this, participants are prone to misconstrue the question, and answer a different question from the intended one. One conspicuous instance of this we encountered in relation to the subtleness of irony in the two versions of Milton's text in Excerpts 2 and 3.

A person who does not understand the word "irony" or "forthright" cannot answer the questions. Dictionaries define irony as the expression of one's meaning by using language that normally signifies the opposite. When the archangel addresses Satan as "courageous chief", he means the exact opposite ("The first in flight from pain"). "Irony" means, originally, simulated ignorance: the ironist pretends to know nothing, not even that what he says is ironical. Hence, his intended meaning is not merely opposite to the explicit meaning, but typically elusive too (dictionaries mention "simulated ignorance" only as etymology, not as part of the meaning). The more elusive the intended meaning, the subtler the irony. In this sense, irony is diagonally opposed to "forthright, outspoken". We thought that as much would be evident to respondents who have "background in literary studies". We were mistaken. 
While the above-mentioned problem could be potentially solved by providing definitions of the key terms, the following problem is more difficult to handle. To ensure that all participants respond to the same performances, with controlled differences between the two versions, we ought to record a continuous reading of the passage inserting pauses at end-stopped lines and other cues for discontinuation, without a pause, at the enjambments. Since, however, most participants have no or little practice in discerning such vocal differences, we ought to generate one or more such pairs of texts to have participants practice before being exposed to the target texts. In this case, however, we could be accused of "putting the expected answer into their mouth".

To summarise, the large number of incoherent responses have a methodological significance since they demonstrate the difficulty in testing responses to complex aesthetic events. While a more careful planning might have been able to minimize the number of "irrelevant" responses, there is no foolproof way to completely prevent experimenter-subject miscommunication in such experiments.

We found in our empirical studies that participants' comments often provide invaluable information that can complement or shed light on the quantitative results. In this case, a comment from one participant confirmed that, at least, some of the incoherent responses reflect misunderstanding of the questionnaire. We believe that open-ended comments from participants should be an integral component in studies of this kind. In addition, it might be helpful to include specific questions to infer whether participants had trouble understanding what they were expected to do. This is important especially for collecting subjective impressions when some participants might simply fail to reach a state-of-mind that allows them to engage in the task.

\section{Theoretical Conclusions}

Wellek and Warren (1949: 152-153) conceive of a poem as of a stratified system of norms that is the potential cause of experience:

Linguists such as the Geneva School and the Prague Linguistic Circle carefully distinguish between langue and parole, the system of language and the individual speech-act; and this distinction corresponds to that between the individual experience of the poem and the poem as such.

In other words, the poem is ontologically incomplete, and much depends on how one realizes it in an actual performance. In our case, the syntactic units and the versification units in an enjambment are given; but they leave 
the reader with a margin of freedom as to how to perform the poem (vocally, subvocally, or mentally): by indicating continuation, discontinuation or both at the line ending.

According to Chatman, in a mental performance all possibilities are open, but in a vocal performance, the performer must choose between two partial, unsatisfactory solutions. We have proposed a third, "rhythmical" performance that obviates the need to choose.

In the case of enjambment and irony, the perceptual quality crucially depends on how the participant performs the enjambment. Briefly, if you perform the poem in such and such a way, then you may perceive such and such qualities; if you perform it in some alternative way, then you perceive some other qualities. In this way, incompatible responses can be accounted for by the same hypothesis in a principled manner. Obtaining different perceived qualities when applying alternative cognitive strategies to a poem does not imply that "anything goes". On the contrary, rather. It has precedent in algebra, where, as every seventh-grade student knows, in the solution of second-degree equations one gets two different, equally correct results, according to whether one applies plus or minus where the formula says \pm before $\sqrt{ }$ (every square root has two values: $+\mathrm{x}$ and $-\mathrm{x}$ ).

The researcher will have to prefer one combination to another, if at all, on theoretical grounds. If s/he believes, for instance, that one must perform an enjambment in such a way that both the syntactic structure and the versification structure should be simultaneously perceptible, s/he will prefer one kind of solution; if $s /$ he believes with Chatman that only two (incomplete) ways to perform an enjambment are possible, s/he may prefer some other solution. At this point, one must invoke Morris Weitz (1962), who says that the role of theory in aesthetics is to make a crucial recommendation what to look for and how to look at it in art. If a literary scholar is not aware that a "rhythmical performance" of an enjambment is possible, s/he may make one kind of decision; if $\mathrm{s} / \mathrm{he}$ encounters in a piece of criticism a crucial recommendation according to which a rhythmical performance is possible, s/he may change his or her way of looking at the text.

A closer look at our conduct in the present article will suggest another important aspect, in contrast to much contemporary scholarship. Quantitative stimulus-response studies must be only a second, confirmatory stage in aesthetic inquiry. It must be preceded by some more theoretical method of establishing the perceptual quality of an aesthetic object. One must, for instance, offer some plausible hypothesis to relate possible perceived qualities to poetic structures - based on a description of the structure of the poem, conflicting perceived qualities reported by competent readers, and the findings 
of such disciplines as psychology, linguistics, ecology, philosophy of language, etc. It is the hypothesis that accounts for the greatest amount of information, at the most fine-grained level, based on the best-established findings of the relevant disciplines that must be preferred (cf. Margolis 1962).

To conclude. The above definition of irony entails that of the four possible combinations only judgments based on combinations 1 and 2 can be true. Assuming two different performances, judgments based on both combinations 1 and 2 support our hypothesis. Recalling Tsur's and Gerber's exchange on Wright's enjambment, Combination 1 presupposes a performance relying on conflicting cues without a pause, Combination 2 presupposes a performance relying on straightforward pause, suppressing continuity. Since enjambment suggests continuation and discontinuation at the same time, a performance relying on conflicting cues without a pause does more justice to the text than a performance relying on straightforward pause, suppressing continuity. As the results show, indeed, judgments based on Combination 1 are the majority; but, as we said, we consider judgments based on Combination 2 too as supporting our hypothesis. Judgments based on combinations 3 and 4 are logically possible only if one acts upon a partial definition of irony, namely, "the expression of one's meaning by using language that normally signifies the opposite", with no implications of "pretended ignorance".

The two judgments (combinations 1-2) that support our hypothesis, form $63 \%$ of the (non-contradictory, decisive) received judgments. The aesthetic quality of a piece of poetry cannot be decided in a democratic way: the quality that receives the greatest number of votes forms the government. We predicted on theoretical grounds that judgments based on combination 1 would best reflect the aesthetic nature of the texts. Indeed, out of all logical combinations, this was the favoured option by far (49\% of the four response patterns). But it can form only a minority government.

Recalling the performances of Excerpt 1, a performance relying on conflicting cues without a pause is less easily available than a performance relying on straightforward pause, suppressing continuity; so, it is most remarkable that we received over twice as many judgments based on the former than on the latter. The simple reason is that, as we have said, this is the performance that does most justice to the text. Our results suggest that those participants whose answers supported our hypothesis resorted to straightforward pause in enjambment only when the other performance was not available for some reason (most performers who intuitively have recourse to conflicting cues without a pause are not explicitly aware of this possibility; "it just sounds all right"). ${ }^{6}$

6 This research was supported by The Israel Science Foundation (grant No. 228/11). 


\section{References}

Barney, Tom 1990. The Forms of Enjambment. Unpublished M. A. Thesis, University of Lancaster.

Beardsley, Monroe C. 1958. Aesthetics, Problems in the Philosophy of Criticism. New York and Burlingame, CA: Harcourt, Brace \& World.

Bishop, Phillip A.; Herron, Robert L. 2015. Use and Misuse of the Likert Item Responses and Other Ordinal Measures. In: International Journal of Exercise Science 8(3), 297-302.

Booth, Wayne C. 1961. The Rhetoric of Fiction. Chicago: The University of Chicago press.

Chatman, Seymour 1965. A Theory of Meter. The Hague: Mouton.

Chatman, Seymour 1966. Intonational Fallacy. In: Quarterly Journal of Speech 52(3), 283-286.

Gerber, Natalie 2015. Intonation and the Conventions of Free Verse. In: Style 49(1), 8-34.

Gerber, Natalie; Smith, David Nowell 2015. A Conversation with Reuven Tsur on Intonation and Prosody. In: Thinking Verse V: 172-212.

http://www.thinkingverse.org/issue05/TsurInterviewIntonation.pdf.

Greene, Roland. 2012. The Princeton Encyclopedia of Poetry and Poetics. Princeton University Press.

Hepburn, Ronald W. 1968. Emotions and Emotional Qualities: Some Attempts at Analysis. In: Osborne, Harold (ed.), Aesthetics in the Modern World, London: Thames and Hudson, 81-93.

Loesch, Katharine T. 1965. Literary Ambiguity and Oral Performance. In: Quarterly Journal of Speech 51(3), 258-267.

Loesch, Katharine T. 1966. Reply to Mr. Chatman. In: Quarterly Journal of Speech 52(3), 286-289.

Margolis, Joseph 1962. The Logic of Interpretation. In: Margolis, Joseph (ed.), Philosophy Looks at the Arts: Contemporary Readings in Aesthetics. New York: Scribner, 108-120.

Meyer, Leonard B. 1956. Emotion and Meaning in Music. Chicago, IL: The University of Chicago Press. 
Nadler, Joel T.; Weston, Rebecca; Voyles, Elora C. 2015. Stuck in the Middle: The Use and Interpretation of Mid-Points in Items on Questionnaires. In: Journal of General Psychology 142(2), 71-89.

Tsur, Reuven 1977. A Perception-Oriented Theory of Metre. Tel Aviv: The Porter Institute for Poetics and Semiotics.

Tsur, Reuven 1998. Poetic Rhythm: Structure and Performance - An Empirical Study in Cognitive Poetics. Bern: Peter Lang.

Tsur, Reuven 2000. The Performance of Enjambments, Perceived Effects, and Experimental Manipulations. In: PSYART: A Hyperlink Journal for the Psychological Study of the Arts. http://psyartjournal.com/article/show/tsur-the_performance_ of_enjambments_perceived

Tsur, Reuven 2012. Poetic Rhythm: Structure and Performance: An Empirical Study in Cognitive Poetics. Brighton and Portland: Sussex Academic Press.

Weitz, Morris 1962. The Role of Theory in Aesthetics. In: Margolis, Joseph (ed.), Philosophy Looks at the Arts: Contemporary Readings in Aesthetics. New York: Scribner, 48-59.

Wellek, René; Warren, Austin 1949. Theory of Literature. New York: Harcourt, Brace \& Co.

Whaler, James 1956. Counterpoint and Symbol: An Inquiry into the Rhythm of Milton's Epic Style (Anglistica 6). Copenhagen: Rosenkilde. 